ISSN: 0213-2079

DOI: http://dx.doi.org/10.14201/shhmo20133599125

\title{
EL PODER Y LA GLORIA: ÉLITES Y ASIENTOS MILITARES EN EL ASTILLERO DE LA HABANA DURANTE EL SIGLO XVIII
}

\section{Power and Glory: Elite and Military Bases in the Havana Shipyard during XVIII Century}

José Manuel SERRANO ÁLVAREZ

Universidad de Antioquia, Colombia

Correo-e: jmserranoalvarez@gmail.com

RESUMEN: El astillero de La Habana reflejaba muy bien a lo largo del siglo XVIII las luchas de intereses entre las élites locales y las necesidades imperiales de España en el Caribe. El poder, asociado al dinero, y la gloria, vinculada a la posición social, fueron los grandes caballos de batalla de la poderosa élite habanera en su colaboración con las autoridades políticomilitares enviadas desde España. Los asientos militares fueron uno de los canales para alcanzar ambos objetivos, y provocaron una continua lucha en torno al vital arsenal militar, fuente de riqueza, poder e intrigas permanentes. Este trabajo dibuja un panorama de una cooperación tan necesaria como forzosa.

Palabras clave: Astillero de La Habana, élites, asientos militares, construcción naval, América siglo XVIII.

ABSTRACT: Throughout the 18th century, Havana's shipyard served to reveal the conflict of interests between the local elite and Spain's imperial needs in the Caribbean. Power, associated with wealth, and glory, which came from social position, were the driving forces of the collaboration between the powerful upper echelons of Havana and the political-military authorities sent from the Peninsula. Military bases were one of the means to 
achieve both ends, and gave rise to endless struggles over the vital military arsenal, a source of riches, power and constant intrigue. This work illustrates the panorama of this cooperation, equally a necessity and an obligation.

Key words: Havana Shipyard, Elites, Military Bases, Shipbuilding, America XVIII century.

Si nos atenemos al número de buques construidos a lo largo del siglo XviII, La Habana, singularmente, debería ocupar un lugar preeminente. No menos de 109 buques de guerra fueron botados de su famoso arsenal entre 1724 y 1796 , de los que 49 fueron navíos de línea y 22 fragatas ${ }^{1}$. Tan solo El Ferrol botó más navíos en el mismo período (54), mientras que de Guarnizo salieron 44, quedando Cádiz (La Carraca) muy lejos con apenas 7 navíos. Sin embargo, ninguno de los últimos arsenales mencionados construyó más buques de guerra en el total que La Habana. Estos datos hablan de la importancia de Cuba como factor constructivo naval militar a lo largo de una centuria en la que el poder marítimo era, con mucho, el más decisivo a la hora de sostener o ampliar los imperios coloniales. Pese a que estos datos son muy conocidos, la historiografía ha olvidado parcialmente el decisivo papel habanero en la política constructiva de los Borbones, y su enorme contribución al sostenimiento del imperio colonial americano. Casi toda la bibliografía se ha centrado en la política naval general (con sus múltiples variables) dedicando apenas unas líneas (o unas notas a pie de página) al astillero de La Habana, y centrando sus análisis sobre los efectos de las diferentes políticas de la Marina de guerra a lo largo del siglo xviI en la península, entendiendo aquí la contribución (decisiva sin duda) de los tres grandes departamentos marítimos de España. Creo no equivocarme si indico que no hay, hasta la actualidad, más de una docena de contribuciones referentes específicamente a la labor constructiva habanera en el Siglo de Las Luces². En este trabajo, por tanto, vamos a tratar de

1. VAldés, A: Historia de la isla de Cuba, y en especial de La Habana. La Habana, 1813.pp. 320-322.

2. De las contribuciones mencionadas, podemos destacar las siguientes: GARCía DEL PINO, C.: «La construcción naval en Cuba hasta fines del siglo XviII. Sinopsis», Revista de la Biblioteca Nacional José Martí (enero-marzo, 1999), pp. 25-30; GARCía DEL PINO, C.: «El arsenal de La Habana durante el siglo XVIII», La Habana, puerto colonial, siglos XVIII-XIX. Madrid, 2000; KUETHE, A. J. y Serrano Álvarez, J. M.: «El astillero de La Habana y Trafalgar», Revista de Indias, 67:241 (2007), pp. 763-776; Prat de Padua, M. y Matamoros Aparicio, D.: «La organización del astillero de La Habana durante el siglo XVIII», Anuario de Historia de América Latina, 34 (1997), pp. 89-103; CERVERA, G. P.: «La bahía de La Habana. Apuntes para su historia», Revista de Historia Naval, 73 (2001), pp. 59-67; Serrano Álvarez, J. M.: «Los inicios del astillero de La Habana en el siglo xviII y la influencia francesa», História, São Paulo, 1 (2011), pp. 287-304; Serrano Álvarez, J. M.: «La revitalización del Astillero de La Habana en época de Lorenzo Montalvo, 1765-1772», Revista de historia naval 27:105 (2009), pp. 71-100; Serrano Álvarez, J. M.: «Juan de Acosta y la construcción naval en La 
incidir en uno de los elementos que privilegiaron a La Habana hasta elevarla a la posición de garante de los intereses españoles en el Caribe y defensora (vía construcción naval) de la hegemonía española en América: la relación entre su poderosa élite local y el astillero.

A lo largo del siglo xviII, La Habana se constituyó en una de las ciudades más importantes de la América española gracias a su posición geoestratégica; posición esta que provenía de su íntima vinculación con el proceso de conquista y colonización del Caribe desde el siglo xvi. La obligación de las flotas y galeones de hacer parada en este puerto antes de retornar a España, la convirtió en un epicentro de poder político y militar, a la vez que permitió a la élite local insertarse en sus organigramas coloniales gracias a las posibilidades económicas de la isla. Las conexiones entre los intereses de los comerciantes del Virreinato y los de la isla se hicieron recurrentes ya desde finales del siglo xvi, y durante el xvir se consolidaron definitivamente. Ni siquiera la desaparición del sistema de flotas y galeones (que se produjo en dos fases: 1765 y 1778) la desplazó de su singularidad. La isla y el puerto habanero siguieron siendo la joya de la Corona en el Caribe, el corazón por el que latía la sangre indispensable para el mantenimiento de su privilegiado estatus militar ${ }^{3}$.

Al margen de las conexiones mexicanas, esta favorable posición había ya arrancado sólidamente en el siglo xvir al socaire de los negocios mercantiles de la élite local relacionados con el tabaco, el incipiente astillero y la administración militar. Todo un complejo entramado se fue gestando en el que los intereses de todas las partes eran coincidentes y concomitantes, a saber, convertir a Cuba en el puente natural militar y comercial entre América y España. Al abrirse el siglo XVIII ya existía una fuerte dinámica económica en Cuba, y en especial en La Habana, asociada en una primera instancia al extraordinario papel dinamizador del tabaco, que ya en esa época suponía más de la mitad de las actividades agropecuarias de

Habana (1717-1740)», Revista de historia naval 24:93 (2006), pp. 7-32; SERrano Álvarez, J. M.: El astillero de La Habana y la construcción naval, 1700-1750. Madrid, 2008. Ortega Pereyra, O.: El Real Arsenal de La Habana: la construcción naval en La Habana bajo la dominación colonial española. La Habana, 1998.

3. Siguen siendo extremadamente útiles las historias clásicas sobre el desarrollo e importancia de Cuba y La Habana, en especial: Pezuela, J. de la: Ensayo histórico de la isla de Cuba. Nueva York, 1842; SAGRA, R. de la: Historia económico-política y estadística de la isla de Cuba. La Habana, 1831; Humboldt, A.: Ensayo político sobre la isla de Cuba. París, 1827; VAldés, J.: Historia de la isla de Cuba, y en especial de La Habana. La Habana, 1834; DE LA TORre, J. M.: Habana antigua y moderna. La Habana, 1857; GÓMEZ, J. M.: Memoria sobre la conservación del puerto de La Habana. Santiago de Cuba, 1831. 
la isla ${ }^{4}$, así como por el cada vez mayor impacto de la sacarocracia, es decir, las poderosas familias asociadas al negocio y comercio del azúcar ${ }^{5}$. Por supuesto, los masivos aunque intermitentes envíos de plata desde México (situados) jugaron igualmente un activo papel dinamizador que empujó a la élite a la participación en sus estructuras de poder porque este dinero en metálico ayudó a la clase comerciante local a conectarse más rápidamente con los negocios de la Monarquía gracias al respaldo de la plata mexicana ${ }^{6}$.

Llegados a este punto, es importante hacer una apreciación sobre el concepto que transversal y permanentemente cruzará este trabajo: la élite. Tradicionalmente, la élite americana ha estado asociada a un grupo (huiremos del término marxista clase por razones obvias) evidentemente privilegiado, pero íntimamente asociado a su estatus nobiliario, o a su procedencia peninsular que, a su vez, estaba fuertemente relacionada con su posición de poder político. Solo basta leer los innumerables trabajos a este respecto para tener una apreciación clara de lo que la mayor parte de la historiografía ha entendido como élite. Me temo que esto ha sido así porque la historiografía post independencia vinculó el proceso de emancipación a la lucha contra el español, así como contra los que ostentaban títulos y prebendas de raigambre claramente medieval. Sin embargo, un personaje muy bien instruido (el famoso Barón von Humboldt) en sus célebres viajes por América tuvo un contacto real y permanente con este denominado grupo elitista, y amplió notablemente su concepción. Para Humboldt, la élite americana (y por supuesto la cubana) estaba constituida por un grupo socialmente extenso, sin vinculación directa (necesariamente) con los títulos, ni forzosamente con su posición en el organigrama de control político americano, cuyos privilegios podían proceder tanto de su poder económico, como de su posición política e incluso intelectual7 ${ }^{7}$. Es más, la élite tradicional española compraba tierras y vivía de las rentas, mientras que la americana era más dinámica y estaba vinculada en mayor o menor medida al mundo de los negocios. O dicho de otra forma, la pertenencia al grupo denominado élite estaría en realidad caracterizada por su posición de superioridad frente al resto de la sociedad, al margen de cualquier condicionamiento previo clásico. De hecho, y en concreto en La Habana, un «simple» carpintero de ribera adinerado pertenecía tanto a la élite como el conde de Macuriges, en los términos en que los estamos

4. Marrero, L.: Cuba: Economía y Sociedad. Santiago, 1972. pp. 35-62.

5. Posiblemente, el mejor estudio específico sobre este importante grupo sea el de ArANGO, R.: La Sacarocracia: Historia de La Aristocracia Azucarera Cubana. Miami, 2006.

6. Al respecto de comprender el papel global del situado en la política americana, véase el siguiente reciente trabajo de conjunto: MARICHAL, C. y GRAFENSTEIN, J. von (coords.): El secreto del Imperio español: los situados coloniales en el siglo XVIII. México, 2012.

7. Moreno Alonso, M.: «Consideraciones de Humboldt sobre las élites indianas», Élites urbanas en Hispanoamérica. Sevilla, 2005, pp. 180-183. 
describiendo, y que también percibió Humboldt. Obviamente, esto no evitaba que hubiera estatus diferentes dentro de la propia élite, y que en última instancia, los ricos comerciantes, o los propietarios enriquecidos, aspiraran a lucir también su propio escudo de armas o la inserción en una orden de caballería. Así pues, será esta más amplia acepción la que utilizaremos respecto de la élite.

La tradición heredada de los Austrias respecto de los asientos militares siguió siendo esencialmente la misma a comienzos del siglo xviII. La participación de actores privados en los negocios de la guerra constituía la norma general, y esta descansaba (respecto de América) en la propia singularidad del proceso conquistador. Como bien destacó (y probó) Antonio Miguel Bernal «la adquisición del Imperio resultó de cuantía insignificante para las finanzas públicas» ${ }^{8}$, por lo que el anclaje de los sectores privados de capital dentro de la administración militar se hizo no solo usual, sino fundamentalmente legal. A finales del siglo XvII, ni siquiera la tan cacareada crisis (que ya sabemos que no fue tal, al menos en su magnitud) repercutió en las formas de administración, control y desarrollo de los negocios asociados a la guerra. Lutgardo García Fuentes ya demostró que las tesis tradicionales de decadencia sostenida en la segunda mitad del siglo XvII eran más un mito historiográfico que una realidad tangible ${ }^{9}$, y que se podía hablar alto y claro de una profunda revitalización comercial desde la década de $1660^{10}$. Un reciente libro apunta precisamente en esa dirección, al indicar que en las últimas décadas del siglo Xvir el aumento de la presión fiscal sobre la Carrera de Indias probaba una fuerte revitalización comercial (y fiscal) que provenía, precisamente, del ámbito americano ${ }^{11}$. Los trabajos de Chevalier argumentaron sólidamente hace ya tiempo que el virreinato de Nueva España y su ámbito de influencia (Cuba) vivió un fuerte crecimiento en términos de acuñación, masa monetaria y comercio interprovincial impidiendo no solo una contracción de las operaciones comerciales, sino además incentivándolas ${ }^{12}$. El gasto militar en el Caribe fue extraordinariamente importante en el último tercio del siglo xvII, algo que no se podría haber producido sin el aporte mexicano, dependiente a su vez de la revitalización de su sector minero ${ }^{13}$.

Todo esto incidía fuertemente en el ámbito cubano de manera muy obvia, ya que Cuba era receptora neta del situado mexicano (aporte fiscal o transferencia

8. Bernal, A. M.: España, proyecto inacabado. Costes/beneficios del Imperio. Madrid, 2005, p. 201.

9. García Fuentes, L.: El comercio español con América, 1650-1700. Sevilla, 1980.

10. García Fuentes, L.: «En torno a la reactivación del comercio indiano en tiempos de Carlos II», Anuario de Estudios Americanos XXXVI, (1979), p. 151 y ss.

11. Díaz Blanco, J. M.: Así trocaste tu gloria. Guerra y comercio colonial en la España del siglo XVII. Madrid, 2012, p. 268.

12. Chevalier, F.: La formación de los latifundios en México. México, 1976.

13. Tepaske, J. J.: «La política española en el Caribe durante los siglos XVII y XVIII», La influencia de España en el Caribe, La Florida y La Luisiana, 1500-1800. Madrid, 1983, pp. 61-67. 
de capitales) y permitía una actividad creciente. Con un fuerte grupo comercial, nexos evidentes con México, y precedentes claros de inserción de la élite local en la maquinaria militar, no resultaba raro que La Habana se convirtiera a ojos de la Monarquía en un factor clave desde comienzos del siglo xviII. Los precedentes además jugaban a su favor. Durante los siglos xvi y xvir, La Habana había elevado su jerarquía de importancia constructiva naval de manera muy patente. A lo largo de esos dos siglos, se firmaron muchos asientos navales que implicaban, recurrentemente, a la élite económica local con el astillero: con la garantía de la plata mexicana y las cada vez más sólidas bases económicas de quienes «arriesgaban» con los negocios, resultaba demasiado tentador no resistirse al negocio naval. Todas las contratas se hicieron mediante asientos privados (siguiendo esa tradición ya comentada) y sentaban unas bases de actuación que se verían ampliamente durante el siglo xviII. Por ejemplo, Juan Díaz Pimienta firmó en 1622 una contrata que, curiosamente, no incluía para él remuneración alguna, sino la promesa de suceder al castellano de la fortaleza de La Fuerza ${ }^{14}$. Esto revela una de las ideas centrales de incluirse en los negocios del astillero: el afán de promoción social vía universo militar. A ciertos negociantes habaneros parecía importarles menos los réditos y beneficios económicos (que en algunos casos eran muy significativos) cuanto que posicionarse de cara a ganancias a más largo recorrido. De hecho, Díaz Pimienta fue más allá en sus servicios a la Monarquía fundando poco después una Sociedad de Armadores que incluía a otros contactos suyos en La Habana (también gente de negocios) lo que le granjeó en su momento la inclusión en la Orden de Santiago en $1642^{15}$. Su hijo, del mismo nombre, recogió los frutos de su progenitor y continuó con los negocios navales a ambos lados del hemisferio, lo que le permitió obtener el Señorío de Villareal, la Capitanía General de Menorca y el almirantazgo general de la Real Armada: un buen rédito, sin duda ${ }^{16}$.

Pese a las ya casi legendarias calidades de las maderas cubanas, y tratarse La Habana de casi el único astillero que construía buques a finales del siglo xvir, al despuntar el siglo xviII el astillero aún no se había ganado el estatus jurídico de principal plaza constructiva en América. Veracruz, Cartagena de Indias y, muy especialmente, Coatzacoalcos, le disputaban tan privilegiada posición. Las causas eran evidentes, ya que el negocio naval era una vía natural hacia el enriquecimiento, el prestigio y el aumento de la actividad económica: había bastante competencia. Diversos factores empujaron a La Habana hasta su posición hegemónica, que no abandonaría en todo el siglo XviII.

14. Serrano Álvarez, J. M.: El astillero de La Habana y la construcción naval, 1700-1750. Madrid, 2008, pp. 40 y ss.

15. Lohmann, G.: Los americanos en las Órdenes Nobiliarias. Madrid, 1993, vol. 2, p. 134.

16. Ibidem, p. 41. 
En 1697 Cartagena de Indias sufrió un brutal ataque y saqueo por parte del almirante francés Barón de Pointis, destruyendo buena parte de sus infraestructuras y empobreciendo las bases económicas locales: un rival menos ${ }^{17}$. El astillero de Coatzacoalcos, en la costa del golfo de México, gozaba del apoyo del gobernador Guiral, quien incluso envió a la Corte un extenso y largo memorial en 1720 contando las bondades de sus maderas y su privilegiada posición: sin embargo, se hizo el silencio ${ }^{18}$. La Habana ganó el «concurso» gracias a una serie de innegables virtudes: un extraordinario puerto, fuertemente defendido y mejor ubicado; una larga tradición constructiva con fama más allá de sus líneas de costa; asientos navales que sistemáticamente se cumplían; cualidades inmejorables de sus maderas; sólida formación de sus trabajadores en la maestranza; la afluencia de la plata mexicana y, principalmente, una capacidad casi inagotable de los agentes económicos locales por insertarse en los negocios del mar e influir políticamente en la toma de decisiones. Veamos algunos ejemplos.

En 1701, el maestro mayor Joseph Ruiz Campos (hijo a su vez de un constructor naval panameño con negocios en el azúcar) había recibido el encargo de construir dos galeones afragatados por el costo total de 39.491 pesos, aparentemente menos costosos que en otros lugares ${ }^{19}$.

Ricardo O'Farrill (de innegable origen irlandés, establecido en La Habana desde 1715 , introduciendo la primera factoría de venta de esclavos ${ }^{20}$ ) había firmado en la década de 1720 un asiento en Cuba para surtir de bombas a la escuadra de López Pintado ${ }^{21}$. Previamente, su éxito «empresarial» con los esclavos le había repercutido con la consecución de la naturalización por Real Cédula de 17 de enero de 1722, abandonando el asiento de negros (ya rico) y enlazando con la élite pura habanera ${ }^{22}$. Inmediatamente casó con María Josefa Arriola, que era hija de Bartolomé de Arriola, proveniente de una de las familias más ricas e influyentes de La Habana y que había sido además contador del Tribunal de Cuentas ${ }^{23}$. Un

17. Serrano Álvarez, J. M.: «La defensa naval de la gobernación de Cartagena de Indias, 16501700», Guerra y Sociedad en la Monarquía Hispánica. Política, Estrategia y Cultura en la Europa Moderna, (1500-1700). Madrid, 2006, pp. 1007-1023; Serrano Álvarez, J. M.; Ruiz Rivera, J. B.; Mogollón, J: «¿Por qué cayó Cartagena de Indias en 1697?» en Cartagena de Indias en el siglo XVII, Cartagena de Indias, 2007, pp. 527-550.

18. NAVARRo, L.: «Política exterior: la guerra», América en el siglo XVIII: los primeros Borbones, vol. XI-1, Historia General de España y América. Madrid, 2010, pp. 119-120.

19. Archivo General de Indias [en adelante, AGI], Santo Domingo, 417, carta de 9 de noviembre de 1701.

20. Fornes, L.: Cuba. Cronología: cinco siglos de historia, política y cultura. Madrid, 2003, p. 32.

21. Quintero, J.: «La madera en los pertrechos navales», Tiempos Modernos, 10, 2004, p. 9.

22. Serrano Álvarez, J. M. y Kuethe, A. J.: «La familia O'Farrill y la élite habanera», Las élites urbanas en Hispanoamérica. Sevilla, 2005, p. 204.

23. GonzÁlez-Ripoll, M. ${ }^{a}$ D.: Cuba, La Isla de los Ensayos- Cultura y Sociedad (1790-1815). Madrid, 1999, p. 140. 
tío de María Josefa, Agustín de Arriola, además había ostentado en 1711 el cargo de alcalde ordinario y gobernador en funciones de Cuba y estaba fuertemente conectado con los negocios e intereses del astillero ${ }^{24}$. Pues bien, María Josefa Arriola se había casado, anteriormente a unirse con el naturalizado O'Farrill, con Miguel Ambulodi, habanero de ilustre familia, de quien tuvo dos hijas no menos ilustres. Una, Teresa Ambulodi Arriola, acabaría casándose con el que sería dueño y señor del astillero de La Habana durante décadas, Lorenzo Montalvo, Conde de Macuriges. La otra hija, Josefa Ambulodi Arriola, se casaría con José del Campillo y Cossío, posterior Ministro de Marina y uno de los padres del resurgimiento naval español del siglo XVIII ${ }^{25}$. Justo cuando la pugna por el asentamiento de un gran astillero en América estaba en efervescencia, Agustín de Arriola solicitó en 1713 a Madrid el establecimiento de dicho astillero en La Habana, y la comunicación e informe fue suficiente como para que fuera trasladado a la ciudad cubana el mismo José del Campillo en 1722 en calidad de Comisario de Marina, sin duda, para tratar el asunto directamente ${ }^{26}$. La «historia de amor» con Josefa Ambulodi sin duda surgió en el ínterin, mientras conectaba con la élite local y ejercía sus labores de Comisario de Marina. En 1725 ya se podía dar por seguro el triunfo de La Habana como astillero principal de América, justo antes del regreso a España de Campillo. ¿Casualidad?

Parece bastante evidente la mano de las élites locales y sus conexiones dentro y fuera de Cuba como causa fundamental del logro esencial de convertir al astillero de La Habana en el eje principal de las actividades constructivas navales en América. Aunque es cierto que la decisión política de convertir a La Habana en el astillero preferencial se tomó en Madrid (provocó una agria disputa entre Bernardo Tinajero, José Grimaldo y Jean Orry), no es menos cierto que la conexión habanera y la poderosa influencia de su élite local jugó finalmente el papel decisivo. Todos los implicados ganaban, porque los ricos y hacendados del lugar tendrían opción de disfrutar de una ventaja doble: o bien se insertaban directamente en los negocios que giraban en torno a la construcción (vía asientos y contratas), o bien se beneficiaban de la aparente seguridad que generaría un astillero militar y una presencia naval permanente. Madrid, por su parte, se garantizaba un programa constructivo permanente y sostenido gracias al apoyo de multitud de actores interesados, incluso, con evidentes conexiones en México.

Aunque ya en 1713 se había firmado un asiento con un peninsular (López Pintado) para la construcción de diez buques de guerra en La Habana, este no

24. Arrozarena, C.: El roble y la ceiba: historia de los vascos en Cuba. Tafalla, 2001, p. 76.

25. GonZÁlez-Ripoll, Cuba, p. 140.

26. Rosain, D.: Necrópolis de La Habana: historia de los cementerios de esta ciudad: con multitud de noticias interesantes. La Habana, 1875, p. 238. 
pudo ejecutar sus obligaciones debido a su escasa presencia física en Cuba, y a que en 1717 apareció en el horizonte un personaje esencial en este periodo ${ }^{27}$.

No sabemos con seguridad cómo el habanero Juan de Acosta surgió con tanta fuerza en la escena del astillero, aunque es más que probable que fuese por las conexiones familiares, ya que su padre, Mateo, Capitán en La Habana, estaba bien relacionado con la sociedad habanera y poseía tierras ${ }^{28}$. En cualquier caso, las primeras noticias significativas que tenemos de él datan de 1717 cuando se le nombró, en atención a sus servicios, alférez de la Compañía de Gente de Mar del astillero. Parece ser que en esta primera etapa estaba a cargo de los guardacostas de la ciudad, ya que sus servicios en este empleo le llevaron a un ascenso como teniente en 1720, pero también empezó a distinguirse como fiel servidor de Su Majestad aprontando y pagando embarcaciones en corso para la persecución de contrabandistas ingleses ${ }^{29}$. Sabemos que gracias a sus amistades con el gobernador, pronto contactó con el mundo del asiento naval, lo que sin duda le otorgó rápida información sobre los comerciantes ligados al astillero, pero no sabemos de qué manera o mediante qué medios dejó a la mayoría de ellos fuera de los negocios. Acosta prestaba dinero para el apresto naval, y ni siquiera solicitaba sueldo, aspectos ambos que sin duda ayudaron a que el Gobernador le recomendara para un ascenso, el Rey aceptó, y el nombramiento como Capitán de Maestranza de La Habana por Real Despacho de 23 de febrero de 1722 fue su primer gran éxito institucional ${ }^{30}$.

Rápidamente se sucedieron los roces con los suministradores habituales del astillero en un momento en que, recordemos, Campillo ya se encontraba en La Habana. En 1725 había tenido duras disputas con los ganaderos locales por el asunto del corte de maderas, al tiempo que botaba los primeros navíos bajo su dirección ${ }^{31}$. Es posible que su aparente altruismo escondiera una ambición desmedida, pero esta ambición sin duda estaba asentada en sus contactos locales: sabemos que era «amigo» del Gobernador Gregorio Guazo Calderón (quien le recomendó para Capitán de Maestranza), su familia estaba bien posicionada, pero además, tenemos la certeza de que estableció una excelente relación con Campillo (quien era de facto su superior inmediato). Una vez este hubo regresado a España en 1726, los problemas para Acosta aumentaron, y se refugió en su innegable fuerte personalidad y el recurso permanente a sus contactos en la Corte. Tuvo fuertes

27. Serrano Álvarez, El astillero, pp. 49-50.

28. Leiva, E. y Torres Cuevas, E.: Presencia y ausencia de la Compañia de Jesús en Cuba. Madrid, 2005, p. 59.

29. Serrano Álvarez, J. M.: «Juan de Acosta y la construcción naval en La Habana (1717-1740)», Revista de Historia Naval, 93 (Madrid, 2006), pp. 10-11.

30. AGI, Indiferente General, 150, N. 25. Relación de servicios, 26 de agosto de 1743.

31. Marrero, L.: op. cit., p. 4. 
disputas con otro constructor local (Pedro de Torres) así como con el nuevo Comisario de Marina, Juan Pinto, quien llegó a La Habana en $1728^{32}$. Acosta era dueño de importantes terrenos cerca de La Habana y fiscalizaba el corte de maderas de manera absoluta. Esto no gustó a Pinto, que veía en Acosta un competidor nada leal. Recordemos que Acosta estaba construyendo navíos sin un asiento firmado, sino mediante un encargo delegado del anterior asiento de López Pintado, y por órdenes expresas de Madrid. El enfrentamiento multidireccional del constructor (incrementado con la llegada de otro nuevo constructor naval desde España, José Miranda) demostró que Acosta tenía poderosos amigos. En efecto, el virrey de México, marqués de Casafuerte, escribió a Patiño para dar su apoyo al capitán de maestranza, dirigiéndole gratificantes palabras de apoyo al decir que «ha dado muestras de su inteligencia en la profesión, como porque en aquel astillero hará más que otro, teniendo muchos parientes y paisanos que le ayudan de veras y grande conocimiento del país» ${ }^{33}$. Estas palabras son altamente significativas, pues prueban que el poder y la influencia de Acosta en el astillero, como otros harán en decenios posteriores, se basaba en los contactos locales, el nepotismo y la cercanía a las oligarquías de poder, a la que sin duda ya pertenecía.

La llegada a la Secretaría de Marina de José Patiño en 1726 sin duda también benefició a Juan de Acosta. No hemos encontrado pruebas directas, pero parece más que probable que la relación de continuidad respecto de la idea de la construcción naval en La Habana entre Patiño y Campillo, y la amistad de este último con Acosta, fueran motivos más que suficientes como para que el padre de la Marina española en el siglo xviII (Patiño) viera con buenos ojos trasladar al plano de la legalidad contractual lo que ya era un hecho consumado, es decir, que Acosta se convirtiera en el asentista y constructor único de La Habana. De esto estamos seguros porque cuando Campillo desapareció en 1743, la estrella de Acosta declinó rápida e inexorablemente.

Lo cierto fue que finalmente, y no sin demasiados inconvenientes, Juan de Acosta se hizo cargo del asiento de construcción naval militar, cuyas cláusulas firmó el 7 mayo de 1731, obligándose a construir 4 navíos de línea de a 64 cañones, uno por año. Fue ascendido a capitán de fragata por despacho de 21 de abril de 1732, y desde ese momento no solo se encargó de la organización y control del astillero habanero, sino también de los aspectos técnicos que rodeaban a la construcción naval.

El problema para el asentista no fue la consecución de la contrata, ni sus innegables dotes para controlar todo el entramado alrededor el astillero, sino que

32. Serrano Álvarez, El astillero, p. 57 y ss.

33. Archivo General de Simancas [en adelante, AGS], Marina, 303, carta de marqués de Casafuerte a Patiño de 1 de agosto de 1730. 
justo en el mismo año de la firma del asiento (1731) apareció en el horizonte el nuevo Comisario de Marina: Lorenzo Montalvo. El enfrentamiento entre ambos (que llegará a alcanzar tintes dramáticos) sin duda reflejaba la pugna de intereses por el control de las prebendas y beneficios que se incluían con cualquier tipo de relación respecto del astillero. Montalvo debió su posterior éxito con la élite local y su encumbramiento a las más altas dignidades precisamente a sus negocios (activos o pasivos) con el astillero. Nacido en Medina del Campo, Valladolid, en 1704, pronto ingresó en la Marina y al parecer realizó labores administrativas en el departamento de Cádiz. Procedía de una familia hidalga, adinerada, pero sin títulos. Es más que posible que fuese en Cádiz donde conoció y se relacionó con Patiño, quien era desde 1717 Intendente General de Marina, superintendente del reino de Sevilla y Presidente de la Casa de Contratación, sita ahora en Cádiz, y fue Patiño quien, al parecer, lo designó personalmente para el cargo de Comisario de Marina en La Habana ${ }^{34}$. Patiño, que sin duda conocía de la existencia de Acosta a través de Campillo, no podía imaginar que ambos hombres se enzarzarían en una agria disputa. Para Acosta sin duda debió ser muy desagradable enfrentarse a un joven de 27 años astuto, inteligente, ambicioso, y lo suficientemente hábil como para percatarse de que su posición como Comisario de Marina sería mucho más sólida si enlazaba directamente con la élite local.

Al principio, parece que ambos hombres se entendieron, o al menos así se deduce del asunto del navío África, botado por Acosta en 1732 y que a su llegada a Cádiz recibiría no pocas críticas de sus técnicos navales. Acosta, para protegerse, envió una carta al rey en la que informaba a principios de 1734 de que gozaba del apoyo de Lorenzo Montalvo y de Patiño y de que probablemente las injustificadas críticas recibidas en la Carraca se debieran a «haber mudado aquel manejo de la Carraca en manos de franceses» ${ }^{35}$. De hecho, la organización del astillero, la compra y traslado de material, la supervisión de las obras y el control indirecto sobre el dinero le hacía mantener muchos contactos con la élite local política y económica, pero también le granjeó no pocos enemigos ${ }^{36}$. El asunto se zanjó con un tirón de orejas a Acosta y con el inicio de los enfrentamientos con Montalvo, a quien sin duda no debió hacerle ninguna gracia que el primer navío del asiento de Acosta (cuya fiscalización última dependía del Comisario) hubiese recibido críticas en España; críticas que a su vez habrían llegado a su mentor Patiño ${ }^{37}$. Lo

34. Crespo Solana, A.: «La acción de José Patiño en Cádiz y los proyectos navales de la Corona en el siglo XVIII», Revista de Historia Moderna y Contemporánea, 6-7 (1994), pp. 35-49.

35. Archivo General de la Marina «Álvaro de Bazán» [en adelante AGM], 7191, Acosta al Rey, marzo de 1734. La indirecta iba claramente destinada a la creciente influencia francesa en la proyección de los navíos españoles a través de varios constructores.

36. Ibídem.

37. Serrano Álvarez, El astillero, pp 66-67. 
que está claro es que a partir de esta época es cuando empezaron las tiranteces con Montalvo, así como el famoso asunto de las maderas.

Gran parte de los hacendados vinculados al negocio del azúcar no veían con agrado los intentos del asentista de monopolizar el corte y suministro hacia el astillero, máxime cuando esas maderas eran necesarias (según los azucareros) para los cajones y demás utilidades. Ahora comenzará una agria polémica entre dos sectores muy marcados de las élites habaneras: una, relacionada con el astillero, y otra que miraba únicamente los intereses comerciales derivados de sus negocios con el azúcar. Esto no significará que la sacarocracia se desvincule completamente del astillero, pero pronto su élite verá un rival formidable, las permanentes obras de construcción naval frente a sus intereses. Esto explicaría por qué Acosta se acercó a las élites y comerciantes que no tenían negocios importantes con el azúcar.

Por ejemplo, en 1735 se firmó un asiento con Pedro de Rojas para el suministro de víveres al astillero, asiento que gozó del beneplácito de Montalvo ${ }^{38}$. Rojas pertenecía a una de las familias más antiguas de Cuba, incluso se la relacionaba con las etapas originales de la colonización de la isla. De hecho, disponía de abundantes tierras y posesiones en los alrededores de La Habana ${ }^{39}$. Dos años más tarde, en 1737, Raimundo Rodríguez y Pedro Campos se hicieron con los asientos de herrajes y motonería para el arsenal ${ }^{40}$. Ambos eran muy conocidos en La Habana por sus negocios vinculados al Cabildo y estaban muy bien relacionados con la élite local. De hecho, Campos, nacido en La Habana en 1684, había entroncado con las élites locales y sus servicios acabarían siendo recompensados con el tiempo: un nieto suyo sería Alcalde de La Habana y recibiría el premio del ingreso en la Orden de Carlos III ${ }^{41}$.

El asunto de las maderas era mucho más grave, puesto que implicaba un potencial enfrentamiento con los grandes hacendados. Por eso Acosta indicó a Patiño que era vital que pudiera disponer libremente de todos los caudales de la hacienda, y no solo en lo tocante a la construcción de navíos sino también en lo referente al apresto de buques y demás gastos navales, en especial las maderas. En caso de que muriese apuntaba que las obras podían ser continuadas sin demora por su hermano el alférez Pedro de Acosta, así como por su hijo, a quien estaba enseñando los secretos de la construcción naval. Se consideraba capaz de poner la quilla de dos navíos al mismo tiempo siempre y cuando dispusiese de medios económicos suficientes y gozara de libertad plena en el uso y administración de los

38. AGM, Arsenales 5514.

39. LeIVA y Torres Cuevas, Presencia, p. 22 y ss.

40. AGM, Arsenales 5514.

41. Cadenas, V. (comp.): Extracto de los expedientes de la Orden de Carlos III. 13 vols., Madrid, 1979, vol. 6, p. 79. 
caudales $^{42}$. Lo más interesante, sin embargo, es que Acosta se ofrecía a suministrar todas las maderas que fueran necesarias en la construcción de navíos si el rey lo estimaba conveniente, lo que significaba en la práctica tratar de conseguir el monopolio absoluto sobre las materias primas primordiales, amén del control total sobre las finanzas habaneras, y de paso, enfrentarse a las élites de la sacarocracia. Lo que es seguro es que Acosta a estas alturas ya controlaba en exclusiva el corte de maderas para el astillero, al fin y al cabo, la materia prima más determinante en la fábrica naval, aunque no sería hasta 1737 cuando, de iure, pudo hacerse con el negocio del apresto de maderas al obtener directamente el asiento de las mismas ${ }^{43}$.

En 1739 apareció en el horizonte otro ejemplo de la inserción de la élite local en el universo del astillero: Pedro García Menocal. Este personaje, nacido en La Habana en 1696, pertenecía a una ilustre familia procedente originalmente de Cantabria, pero que a lo largo del siglo xvi había ya obtenido una sólida posición política y económica relacionada con el Cabildo. Había logrado sin mucha dificultad la hidalguía y además había casado con Francisca Pérez de Velasco Espinosa, originaria de una de las familias más antiguas de Cuba. En 1735 lo encontramos ya como Contador del Tribunal de la Santa Cruzada ${ }^{44}$. Su holgada posición económica, y el hecho de que estuviese vinculado a los negocios como Contador, le llevó a ver en el astillero una gran oportunidad de aumentar su prestigio y su capacidad económica. En ese año de 1739, y junto con Raimundo Rodríguez, lo vemos firmando nada menos que cuatro asientos con el astillero: víveres, herrería, calderería y armería ${ }^{45}$. El hecho de que estos asientos los firmara junto con su socio Rodríguez prueba no solo que se conocían, sino que además estaba íntimamente ligado a los mecanismos de poder locales, en especial con aquellos que enlazaban con familias antiguas. El poder de los García Menocal se hizo patente desde entonces: Pedro, no solo continuó con el asiento varios años, sino que en 1744 obtuvo el cargo de Síndico Procurador de La Habana y nada menos que Director de la Factoría de Tabacos ${ }^{46}$. La influencia de los García Menocal sobre los negocios del tabaco acabaría siendo legendaria, y en gran medida se debió a que enlazaron sin dificultad con otras familias de similares intereses ${ }^{47}$. Con el establecimiento definitivo de la Compañía de La Habana en 1741 (cuyo principal interés era el tabaco), un hermano de Pedro, Bartolomé García Menocal, consiguió

42. AGM, Arsenales 7191, Acosta a Patiño, 11 de noviembre de 1734.

43. AGM, Arsenales 5514.

44. Cortadellas, R. N.: Genealogías habaneras. Madrid, 1979, vol. 2, p. 324.

45. AGM, Arsenales 5514.

46. Cortadellas, Genealogías, p. 318.

47. En las primeras décadas del siglo $\mathrm{Xx}$, incluso un descendiente de estos sería proclamado Presidente de Cuba: Mario Gabriel García Menocal, firme defensor de los negocios del tabaco insular. 
el asiento para surtir de carne fresca y víveres al astillero habanero en $1746^{48}$. No creo que sea coincidencia que poco tiempo antes, en 1742, Bartolomé obtuviera el cargo de Mayordomo de Propios y Rentas de la ciudad de La Habana, ya que esta designación le avalaba como un firme conocedor de las posibilidades de negocios e ingresos fiscales con el enlace de los negocios del astillero y el tabaco a través de su hermano ${ }^{49}$.

En 1735 el astillero había modificado su ubicación para hacerlo más grande y capaz de construir varios buques al mismo tiempo. Su nuevo emplazamiento, denominado La Tenaza, podía, en teoría, albergar hasta tres diques secos para la construcción al mismo tiempo, mientras que todos los almacenes se concentraban a su alrededor. Acosta fue, junto con Montalvo, defensor de este traslado, pero la excesiva ambición de Acosta le iba a pasar factura. El constructor y asentista se obcecaba en construir varios navíos al mismo tiempo sin tener en cuenta las dificultades económicas y, por supuesto, enfrentándose permanentemente a Montalvo. Esto provocó movimientos de intereses de otros actores para desplazar a Acosta y lograr los beneficios asociados al astillero. Es así como entró en escena la Compañía de La Habana, fundada en 1740, y asociada íntimamente al tabaco. Después de algunas discusiones y una intensa negociación, la Compañía logró el asiento de construcción naval firmado el 4 de junio de 1741, pese a que el presidente de la Compañía, Martín Aróstegui, se había mostrado reticente a embarcarse en la desconocida tarea de la fábrica de bajeles para el rey ${ }^{50}$.

Las cláusulas fundamentales de este asiento en lo tocante a la construcción eran muy claras:

(...) se obligó por tiempo de diez años a tener construidos enteramente en cada uno, y votados al agua, tres o cuatro bajeles del porte que S.M. prescribiese, bajo de las medidas que señalase el constructor (...) recibiendo en tres plazos la paga de setenta y cinco mil pesos por uno de setenta cañones; de sesenta y seis mil, por el de sesenta y seis cañones; sesenta mil por el de sesenta cañones; por la fragata de cincuenta y seis cañones, cuarenta y nueve mil pesos; por la de cuarenta y seis cañones, treinta y seis mil pesos; por la de cuarenta cañones, veinte y seis mil pesos; y por la de treinta, diez y nueve mil pesos ${ }^{51}$.

La compañía se obligaba también a hacer la motonería a los buques, aspecto este que no entró en el antiguo asiento de Acosta, así como a compartir con este

48. AGM, Arsenales 5514.

49. Cortadellas, Genealogías, p. 323.

50. GÁrate, M.: Comercio ultramarino e ilustración. La Real Compañia de La Habana. San Sebastián, 1993, pp. 65-66.

51. AGM, Expediciones a Indias, 25, hay copia también en el Archivo General de Simancas [en adelante AGS], Marina, 645. 
la madera para el arsenal. En caso de que se le solicitase, debía también proveer de maderas a los arsenales peninsulares, así como a proveer, por el mismo tiempo de diez años, las raciones ordinarias y de dietas, géneros sueltos y otras piezas para los navíos de Armada destinados a este puerto con un descuento del $5 \%$ en relación con el asiento que tenía Pedro García Menocal. También debía ampliar el arsenal con un nuevo y fuerte cercado de paredes altas y al calafateado completo de los navíos ${ }^{52}$. Paralelamente, el asiento cercenaba, legalmente, los poderes antes omnímodos de Juan de Acosta. El punto xxi del contrato indicaba que en el astillero se encontraban los constructores Pedro de Torres, Juan de Acosta y Juan de Mora, y que sería el rey quien decidiera quién se encargaría de la dirección de las obras. Finalmente se nombró a un peninsular, José de Azueta, la dirección absoluta de la construcción de bajeles, aunque interinamente se dispuso que ocupara ese puesto Pedro de Torres, precisamente el enemigo más acérrimo que tuvo Acosta en su etapa de asentista. De igual forma, a la Compañía se le otorgaron algunas facilidades en la adquisición de materiales, traslado y utilización de espacios, y otras prebendas. Algunos de estos beneficios eran: 1) Poder adquirir los materiales para la construcción y carenas de navíos, 2) Traer el hierro y demás géneros necesarios para dicha construcción, libres de derechos reales, 3) Comprar los ganados para la provisión de armada, a precios corrientes, 4) Ocupar para almacenes el sitio necesario en las obras destinadas para los fines del Real Servicio fuera del astillero, 5) Adquirir los víveres y géneros de la provisión de su cargo en la isla y faltando en ella, donde los hubiere, sin pagar derechos reales por su entrada, y 6) Tener las haciendas de ganados que fuesen necesarias y fletar con antelación los buques, carros y bestias que hubiese menester, todo a los fines de su obligación ${ }^{53}$. Además se le permitía, fiscalizado por el ministro de marina, usar libremente los montes de la isla para el corte de maderas, tanto a sotavento como a barlovento, prohibiéndose a cualquier otra persona el uso de los mismos.

Este asiento supuso el fin de Acosta y sus poderes en el astillero, pero también una modificación de las formas que se adoptaban allí en cuanto a los asientos. La inserción de la Compañía de La Habana, con una muy fuerte fiscalización de Montalvo, suponía lo más parecido a que el Estado se hiciera cargo de la construcción naval. La permanente fiscalización de las labores de una Compañía que, aunque privada, debía sentirse permanentemente controlada por Montalvo y el Ministro Ensenada ayudó en gran medida a que el propio objetivo del asiento (para la Compañía) fracasara. Las enormes pérdidas que sufrió con la construcción naval influyeron, sin duda, decisivamente a que desde la cancelación del asiento, en 1749 , todas las contratas referentes al astillero se hicieran por vía privada y

52. Serrano Álvarez, El astillero, p. 96.

53. AGS, Marina, 645, informe de 19 de diciembre de 1748. 
no mediante con consorcio mercantil. Además, la posición de Montalvo no cabe duda que influyó, viendo en las actividades de la Compañía una cortapisa a sus intereses particulares, que en gran medida estaban asociados a las élites locales. De esta forma, mediante el decreto de 23 de junio de 1749, el rey eximió a la Compañía de las fábricas de bajeles y canceló el asiento, aunque con fuertes condiciones. El rey aceptaba el ofrecimiento de 60 acciones de la Compañía valoradas en 30.000 pesos, que se concluyeran a los precios fijados oficialmente en el asiento los navíos ya iniciados, que se librara a la tesorería local de pagar las mejoras introducidas por la Compañía en el arsenal -tal y como estaban fijadas en el asiento original de 1741-, que se rescindiera el contrato de víveres que tenía con el arsenal y finalmente que se vería obligada la Compañía a conducir de su cuenta los navíos que se estuvieran ya fabricando para suministrarle el armamento ${ }^{54}$.

La importancia de los recursos financieros y la actividad económica generada en torno al gran astillero habanero resalta aún más si se la compara con las otras dos grandes actividades económicas de la isla, como eran el tabaco y el azúcar. Lo que sí está claro es que la incorporación de la industria naval al conjunto de la actividad económica de La Habana fue decisiva para su posterior despegue en la segunda mitad del siglo XVIII ${ }^{55}$. Los datos demuestran que entre 1723 y 1750 entraron en la tesorería de La Habana una media de 227.000 pesos destinados a la compra de la producción tabacalera, habiéndose destinado efectivamente a estos fines más del $90 \%$ de la cantidad recibida ${ }^{56}$. Eso significa que la industria del tabaco no estaba demasiado distante de la economía y las transacciones en el ámbito del astillero. Y a todo ello hay que indicar que para la misma época, aunque sin disponer de datos completos, parece que las rentas del azúcar solo eran un $14,7 \%$ más elevadas que las del tabaco ${ }^{57}$. Por consiguiente, tampoco la industria del ingenio estaba muy por encima de la actividad del astillero. Esto viene a confirmar que la actividad militar de La Habana, lejos de constituir un lastre para la economía local, generaba no pocos beneficios y movía a un elevado número de personas girando en torno a sus múltiples actividades. El negocio de la guerra era, una vez más, una cuestión de simples números, siendo para La Habana, una fuente de ingresos muy bien recibid $a^{58}$.

Respecto a la inserción de las élites en el astillero, los datos hasta aquí son bastante concluyentes. Todas las grandes familias habaneras tenían activos en mayor o menor medida en la Compañía de La Habana, y esta fue la responsable

54. AGS, Marina, 645.

55. KuETHE, A. J.: «Havana in the Eighteenth Century», Atlantic Port Cities, Economic, Culture and Society in the Atlantic World, 1650-1850, 1991, pp. 17-19.

56. Archivo General de Indias, Contaduría 1167.

57. MARRERO, Cuba, p. 39.

58. KuETHE, Havana, p. 18. 
del principal y más costoso asiento naval de la década de 1740. Así pues, aunque no directamente, la participación de los apellidos más prominentes de la isla quedó asegurada mediante la firma del asiento de construcción naval de la Compañía que, como ya se ha visto, resultó un negocio muy poco rentable para sus accionistas. Los asientos firmados por los García Menocal, todos a partir de 1739, hacen pensar que llenaron el hueco que fue dejando la defenestración de Juan de Acosta como el gran «cacique» del astillero. De hecho, ambos eran accionistas de la Compañía de La Habana, y tenemos constancia de que cuando la firma del asiento de construcción naval con la Compañía en 1741, se hizo mención expresa sobre los precios ofrecidos anteriormente por Pedro García Menocal en el asiento de vituallas ${ }^{59}$.

Por otra parte, Francisco Casaubón, que había firmado un asiento sobre la jarcia en 1743, poseía importante capital en la Compañía. El caso de Juan Miralles, cuyo asiento para surtir de pertrechos data de 1747, es realmente curioso. Llegó a La Habana con 27 años y la suficiente fortuna como para pedir la mano de María Josefa Eligio de la Puente y González-Cabello, miembro de una de las más acaudaladas familias habaneras de la época, con fortuna asentada en la Isla y en la Florida: hacia esta última se dirigió tempranamente la actividad comercial de Miralles, negociando con los principales puertos de las colonias inglesas en Norteamérica. Sin embargo, este emprendedor joven Miralles, que más tarde se haría famoso por los contactos con Norteamérica durante el turbulento período de su independencia, detectó con rapidez las posibilidades del negocio naval, y no dudó en asociarse con José de Lugo y Molina, Juan Tomas de Jáuregui, este último uno de los personajes más poderosos de La Habana. El asiento que firmaron los tres, en 1747, sobre los pertrechos de los almacenes del astillero, era uno de los más importantes debido a las enormes sumas necesarias como inversiones en este apartado. Mediante esta relación entre Miralles y Jáuregui, es posible detectar el importante papel que tenía la sociedad habanera en el reparto de los negocios locales. Juan Tomás de Jáuregui llegó a La Habana desde España en la década de los 30 , donde había nacido en 1723. Sin embargo, lo más significativo fue que la firma de este contrato en 1747 le puso en contacto directo con la alta sociedad habanera, hasta tal punto que en 1752 contrajo matrimonio con María de los Ángeles Aróstegui y Bassave, hija del poderoso en influyente Martín de Aróstegui, presidente de la Real Compañía de Tabacos. Esta relación le ayudó, obviamente, a relacionarse a dos bandas: por una parte, con los negocios de la Compañía (que ya se ha visto que en gran medida estaban relacionados con el astillero), y por otra con los asientos concretos que firmaba en asociación con otros importantes comerciantes locales. Este caso, como el de muchos otros, es una muestra de la profunda imbricación que tenía la sociedad habanera en los negocios locales,

\section{SERrano Álvarez, El astillero, p. 130.}


cuyas fortunas y méritos se mezclaban, algunas veces confusamente, en varios negocios al mismo tiempo ${ }^{60}$.

La actividad constructiva en el astillero se vio bruscamente interrumpida en 1762 con la conquista de La Habana por los ingleses; un revés que sin duda nadie esperaba. Las causas de este suceso no toca analizarlas aquí, pero sus consecuencias (una vez pasaron los primeros tiempos de shock) no fueron ni mucho menos negativas, al menos, a largo plazo ${ }^{61}$. Entre 1764 y 1765 se llevaron a cabo vertiginosas reformas en Cuba que implicaban directamente a La Habana y a su astillero, entre las que destacaba, sin duda alguna, la creación de la Intendencia en manos de Montalvo. El otrora «simple» Comisario de Marina veía así incrementado su poder e influencia en los negocios navales con una institución que ya venía funcionando con éxito en la península, y que tras el drama de 1762, las autoridades estimaron conveniente «probar» su implementación en Cuba.

Sin embargo, la posición de Montalvo como Intendente ya venía de lejos al menos de facto. Resulta sumamente curioso (y a mi entender tiene mucha relación con el tipo de contratos que venían vinculando a la élite con los negocios navales) que el astillero de La Habana, pese a su innegable importancia, carecía de un estatus legal claro. En España el marco jurídico-institucional de cada uno de los tres departamentos navales nadie lo discutía, así como su jerarquía interna. El control que allí se tenía de las contratas navales estaba sin duda relacionado con la posición del Intendente de Marina y su cercanía con Madrid, desde donde el Secretario de Marina podía ejercer una fiscalización clave y directa. En cambio, La Habana disfrutaba de la hegemonía entre todos los astilleros de América (como ya hemos visto), y fueron hacia Cuba donde se dirigían todas las miradas para incrementar la potencia naval militar de España. Pese a que esto resultaba muy evidente, a nadie se le ocurrió dotar al astillero de un marco legal e institucional claro. Montalvo, hábil como pocos, sabía de esta carencia, y la aprovechaba en su propio beneficio, en especial después de que Acosta desapareció de escena. Las causas de este vacío legal son bastante difíciles de entender si no se tiene en cuenta que Cuba dependía de la plata mexicana, y de que la posición del Virrey como máxima figura política en el Virreinato lo convertía en garante y ejecutor de decisiones político-económicas en una isla que, jurisdiccionalmente, estaba dentro de la órbita de influencia de la Nueva España. Así las cosas, crear una Intendencia naval en La Habana legalmente, habría supuesto un difícil dilema y

60. Ibidem, pp. 131-134

61. A este respecto, pueden consultarse: PARCERO, C.: La pérdida de La Habana y las reformas borbónicas en Cuba (1760-1773). Valladolid, 1998; VÁZQUEZ CIENFUEGOS, S.: «La Habana británica: once meses claves en la Historia de Cuba», Metodología y nuevas líneas de investigación de la Historia de América. Burgos, 2001, pp. 133-146; CERVERA, G. C.: Inglaterra y La Habana, 1762. La Habana, 2007. 
un grave choque de intereses y competencias, máxime si se tiene en cuenta que en 1764 se creó la Intendencia de Ejército tras las conocidas visitas del Conde de Ricla y el mariscal O’Reilly ${ }^{62}$.

Catorce años antes de que esto ocurriera, el Gobernador de Cuba Cagigal ya le había espetado a Montalvo que sus actuaciones como intendente no tenían base legal, y que estaba sujeto a una jerarquía que, pasando por él, llegaba hasta el propio Virrey. El inefable Montalvo ni se inmutó: dejemos que sean sus propias palabras las que lo aclaren:

No puedo afirmar que este puerto esté declarado por Departamento, cuando no consta en las Ordenanzas generales de Marina; pero sí que en él reside una escuadra, que hay un astillero o arsenal, donde tengo la misma autoridad y facultades que cualquiera de los Intendentes en su Departamento; que se fabrica una Machina y muelle para arbolar y desarbolar, y carenar los bajeles, y unos almacenes para su armamento y desarmo; que se construyen navíos para la Real Armada, y que Su Majestad me mantiene en este puerto, como Ministro Principal, encargado de más de veinte años a esta parte de todas las dependencias de marina de él, lo que no obstante ser tan público y notorio podrá VE confirmar por el título de Comisario de Guerra de que está tomada razón en esa contaduría de Real Hacienda (...) Con que si no es Departamento, es lo mismo que si lo fuese, para la uniformidad y regularidad del servicio, facultad, representación y autoridades $(\ldots)^{63}$.

Estas palabras auguraban cuál iba a ser la posición de Montalvo en el futuro. Así, cuando entre 1764-1765 se implementaron las grandes reformas en Cuba con la creación de la primera Intendencia de América, el astillero habanero adquirió, gracias al papel protagónico y a la personalidad de Montalvo, la categoría de Intendencia de Marina. Imaginemos por un momento la creación oficial de un Departamento naval en La Habana con su intendencia al uso. Teniendo en cuenta la existencia de una Intendencia de Ejército, esto habría creado nada menos que cuatro niveles de autoridad, y una infinita posibilidad de choques jurisdiccionales: un Intendente de Marina, un Intendente de Ejército, el Gobernador de Cuba, y el Virrey. Si a esto añadimos las enormes cantidades de dinero que se movían en Cuba procedente de México, las luchas por el control dinerario habrían sido permanentes.

En este punto, nos encontramos con grandes dificultades. Ningún documento menciona expresamente a Montalvo como Intendente de Marina, y de hecho, ninguno de sus sucesores fue nunca llamado así. Sin embargo, disponemos de

62. Amores Carredano, J. B.: «El intendente de La Habana Juan Ignacio de Urriza y la política imperial de Carlos III (1776-1787)» en González Enciso, A. (ed.): Navarros en la Monarquía española en el siglo XVIII. Pamplona, 2007, pp. 185-214.

63. AGS, Marina, 401, Montalvo a Cagigal, 11 de noviembre de 1750. 
una Real Orden de 17 de marzo de 1763, en la que se confería el nombramiento a Montalvo como Intendente, más no, curiosamente, la Intendencia como tal ${ }^{64}$. En mi opinión, nunca existió de iure Intendencia de Marina en La Habana, y solo se concedió a Montalvo el título de Intendente a efectos honoríficos. Otra cosa muy distinta es que el astillero, en efecto, funcionara como una Intendencia naval.

En este sentido, uno de los aspectos que los historiadores no han tenido en cuenta es que antes de 1765 existían en La Habana tres tesorerías diferentes: la Tesorería General (fiscalizada en primera instancia por el Gobernador), la tesorería de construcción del astillero, y la tesorería de subsistencia de escuadras. Estas dos últimas estaban controladas por el Comisario de Marina, pero la de subsistencia de escuadras estaba directamente supeditada a los fondos provenientes de la Tesorería General, es decir, del Gobernador, entre otras cosas porque sus fondos provenían de los que se enviaban de México (el Virrey) para la escuadra guardacostas de Cuba. Ya antes de 1765 se habían producido fricciones entre los gobernadores y el Comisario Montalvo por este asunto, pero después de esa fecha se produjo una importante reforma fiscal: ambas tesorerías navales se fusionaron desde el 1 de marzo de ese año, y sus fondos únicamente podían ser fiscalizados por el Comisario-Intendente Montalvo. Desde ese momento los envíos de plata de México claramente se diferenciaban cuando eran destinados al ejército, y por tanto a la Intendencia (ingresando directamente en la Tesorería General), y los que estaban destinados al arsenal, que entraban directamente a la Tesorería de Marina, ahora unificada, y bajo control exclusivo de Montalvo y sus sucesores. Esto tuvo una gran importancia a la hora de calibrar las contratas y asientos navales,

64. Hay cierta controversia (o dificultad) en orden a determinar la fecha exacta de la creación de la Intendencia de Marina de La Habana. Sin embargo, un documento del Archivo General de Simancas (Dirección General del Tesoro, inv. 2, 13g 47. Títulos de Indias) especifica con claridad el nombramiento de Montalvo como Intendente de marina en la fecha mencionada de 17 de marzo de 1763 como «premio» por los servicios prestados por Montalvo durante el sitio de 1762. Ya se ha visto que Montalvo actuaba a efectos prácticos como intendente, pero habría que esperar hasta 1763 para ver cumplidos sus sueños. Lo interesante es que la Intendencia de marina, como institución, no aparece en el Real Decreto de nombramiento, sino únicamente el cargo. El historiador Juan Bosco Amores Carredano considera que la creación de la Intendencia es muy posterior a esta fecha, probablemente de finales del siglo xviII, aunque desconocemos la fecha exacta en el caso de que exista tal documento legal. En el caso que nos ocupa (la relación de poder en La Habana en torno al astillero) parece de poca trascendencia la creación oficial de su creación, toda vez que la institucionalización de la Intendencia habría supuesto la implementación de un aparato burocrático completo, a la manera de las Intendencias navales peninsulares, algo que sin duda habría chocado con las diferentes esferas de poder allá, es decir, el intendente del ejército, el gobernador de la isla (que residía en La Habana) y el propio virrey de Nueva España (que sufragaba no poco de los gastos navales habaneros). Por consiguiente, nos postulamos en que lo verdaderamente importante era el ejercicio del cargo de intendente naval (ya legal desde marzo de 1763) y no la propia institución, cuya creación habría supuesto un incremento de los choques de intereses personales y de poder en La Habana, ya importantes desde comienzos de siglo. 
que a partir de esta fecha adquieren un carácter más heterogéneo y privado que antes. De hecho, afectó directamente a la inclusión de los grandes apellidos en el universo de los negocios del astillero, que parecían estar más interesados en sus relaciones políticas con el Gobernador debido a las más rápidas posibilidades de ascenso social a través del ejército, y amparándose en el fuero militar. Al mismo tiempo, una parte significativa de esa élite vinculada a los negocios del azúcar y el tabaco, no asumió bien los «peligros» que representaba el astillero, cuyos fondos y contratas dependían únicamente del poderoso Montalvo. Es a partir de este momento cuando se va a generar una fuerte disputa entre un poderoso grupo de hacendados vinculados a los ingenios y el astillero a causa del reparto de las maderas. La consecuencia inmediata de este proceso de desvinculación de muchos de los grandes apellidos de La Habana respecto del astillero es que será la «otra» élite comerciante criolla la que se insertará decisivamente en los asuntos navales.

Los números son bastante elocuentes al respecto. Entre 1734 y 1761 (antes de la caída de La Habana y de las reformas) tenemos constancia cierta de que se firmaron 16 asientos navales, aunque de estos, los de Acosta y la Compañía de La Habana no solo eran los más importantes, sino que además gozaban de un privilegiado estatus de monopolio. Sin embargo, entre 1762 y 1796 (fecha en que hemos detectado el último asiento) se firmaron nada menos que 47 contratas navales que involucraban a más de una treintena de personajes distintos. Si exceptuamos 3-4 de estas contratas, ninguna alcanzó privilegios que pudiesen ser entendidos como monopólicos. La mayoría de los firmantes de estos asientos post-reformas pertenecían a estratos de la élite no vinculados a cargos públicos ni a familias ya muy conocidas en el entorno habanero. Podemos afirmar que el $80 \%$ de estos contratistas se situaban en el rango medio de la élite; disfrutaban de negocios y buenos contactos mercantiles, y algunos de ellos, llegaron a alcanzar muy altas cotas de poder e influencia en La Habana, aunque comenzando desde abajo.

Por ejemplo, Félix de Hita y Salazar era hasta la década de 1760 un exitoso comerciante criollo en La Florida que tras la conclusión de la guerra en 1763 se trasladó a La Habana. Todos sus antepasados habían sido militares en La Florida, alcanzando alguno de ellos altos cargos. Estos antecedentes le hicieron obtener en la década de 1750 el rango de cadete, honor reservado únicamente a los nobles, hidalgos, o hijos de militares de lustre y trayectoria familiar ${ }^{65}$. Una vez en La Habana, a donde se trasladó tras la guerra con Inglaterra, y en apenas dos décadas, logró convertirse en un rico e influyente asentista del astillero, tan notablemente rico, que se permitió el lujo de prestar dinero a la Real Hacienda. Sus méritos para con la Corona le permitieron que su hijo ingresara como cadete

65. Kuethe, A. J. y Serrano Álvarez, J. M.: «La pérdida de la fidelidad cubana: una perspectiva del siglo XVIII» en Nación y cultura nacional en el Caribe hispano. Praga, 2006, p. 207 y ss. 
en el elitista regimiento miliciano local, y él mismo llegó a ser subteniente. Cuatro comandantes diferentes del astillero (Francisco de Borja, el marqués de Camachos, Javier Morales y Juan Araoz) avalaron su petición de ingreso en el escalafón militar. Félix de Hita firmó en 1765 el más importante asiento de víveres para el astillero ${ }^{66}$; asiento que mantuvo férreamente durante dos décadas. A fines de la década de 1780 era uno de los hombres más conocidos, ricos e influyentes de La Habana. Su caso muestra lo que se podía hacer con iniciativa, contactos y mentalidad empresarial. Cuando llegó a La Habana no era más que un cadete con amplia tradición militar familiar, pero supo jugar sus bazas con habilidad y relacionarse con los personajes que le podían ayudar.

En 1768, Anastasio García Menocal obtuvo el importante asiento para el desarbolo de navíos en el astillero. Anastasio era sobrino de los García Menocal mencionados arriba y constituye uno de los pocos ejemplos de continuidad familiar de vinculación mediante asientos a lo largo del siglo xviI. Este hecho muestra que la extraordinaria diversificación de los asientos en la segunda mitad de siglo había provocado una mayor competencia por los jugosos contratos, y una mayor dificultad de acceder a ellos simplemente por tradición familiar. Tanto Montalvo como sus continuadores siguieron una política muy clara respecto a las contratas navales: gracias a la cuasi independencia económica que poseía el Comandante del astillero (recordemos aquí la Tesorería de Marina independiente) disponían de mayores posibilidades para demandar buenos asientos en beneficio del Rey.

Otro elemento que influyó en la dispersión de los asientos navales fue la puesta en marcha de la Junta de Marina o del Apostadero, que ya funcionó con Montalvo, pero que se haría mucho más importante tras su muerte en 1774. Esta Junta era la encargada de indicar las necesidades del astillero, de promover la pública promoción de sus actividades, y de decidir quién y en qué términos se firmaría una contrata. Dicha Junta estaba conformada por el Comandante del astillero, el Comisario de Guerra de Marina y varios altos cargos navales, usualmente ingenieros y técnicos. En tiempos de Montalvo, esta Junta actuaba según los deseos y criterios del Conde de Macuriges sin apenas oposición, pero tras la desaparición de tan importante personaje, la Junta parece que actuó con criterios más técnicos y económicos que clientelares. Esto explicaría por qué de estos 47 asientos tras 1762, 32 fueron firmados después de la muerte de Montalvo, y por qué la mayoría de ellos tuvieron como protagonistas a «desconocidos» y no a los habituales prohombres de la ciudad.

A partir de ahora veremos cómo serán los negocios vinculados al astillero los que permitan un ascenso en el escalafón social, más que una apuesta desde una posición previa de privilegio. Veamos, sin embargo, alguna excepción.

66. AGM, Arsenales 5514. 
José Manuel López Ganuza pertenecía a una familia muy conocida por sus negocios en La Habana, así como por su antigüedad y contactos. Los López Ganuza habían emparentado con varias influyentes familias locales, y consta que eran amigos de las más prestigiosas fortunas y títulos de la isla, entre ellos Jose Antonio de Beytia, Antonio Armenteros (caballero de Alcántara) o Ignacio de Jústiz ${ }^{67}$. José Manuel de hecho era un habitual prestamista de la Tesorería de Marina, lo que le posicionó perfectamente para conseguir el asiento de estopas en 1781, manteniéndolo hasta finales de siglo ${ }^{68}$. Los beneficios no se hicieron esperar, y al poco tiempo obtuvo el cargo de Síndico Procurador General, y en 1794 nada menos que el nombramiento de caballero de la Orden de Carlos III ${ }^{69}$.

Esta sería una excepción. Hemos detectado más de una veintena de asientos en los últimos treinta años de actividad constructiva del astillero cuyos titulares pertenecían a élites menores de la ciudad. De hecho, algo insólito, en 1779 se probó la contratación directa de construcción de navíos de tres y dos puentes nada menos que a varios consorcios de carpinteros, calafates y maestres de obras privados, cuyos nombres son desconocidos, pero que pudieron reunir suficiente capital (más de 70.000 pesos) para hacerse acreedores de tan arriesgada actividad ${ }^{70}$. Entre 1779 y 1796 todos los asientos, excepto los de Francisco Castellón, Juan Antonio Valdés Navarrete y Gabriel Valdés Navarrete (hijo del anterior) fueron otorgados a personas sin brillo social, pero sin duda con suficiente poder económico como para enfrentar los retos de finales de siglo. ¿Estaban algunos grandes apellidos de La Habana tras las contratas de estos «desconocidos»? A día de hoy no lo sabemos, pero está claro que el universo naval del astillero habanero había sido siempre un imán para las familias locales, para los comerciantes arriesgados, para los negociadores sin escrúpulos, y para todo aquel que desde una posición económica o social de cierta prestancia percibiera en la construcción naval un medio para lograr un fin, más allá del rédito mercantil.

Como conclusión indicaremos que, con los datos hasta ahora analizados (huelga decir que este tema amerita una investigación realmente extensiva) la relación entre la élite local habanera (en toda su expresión) y el astillero constituyó una de las simbiosis más beneficiosas para los intereses de la Marina de guerra española en el siglo xviII. Sin esa relación (que hemos podido mostrar en sus grandes líneas) difícilmente el poder naval habría podido repuntar en la segunda mitad del XVIII de la manera en que lo hizo. Todos los elementos apuntan a que las élites vieron

67. Cadenas, V.: Caballeros de la Orden de Santiago que efectuaron sus pruebas de ingreso durante el siglo XIX. Madrid, 1993, p. 39.

68. AGM, Arsenales 5514.

69. Cadenas, V. (comp.): Caballeros de Carlos III. Extracto de sus expedientes (1771-1847), vol. 4. Madrid, 1982, p. 8.

70. AGM, Arsenales 5514. 
en el astillero de La Habana un recurso natural no solo para el incremento de sus actividades mercantiles, sino también para la obtención de réditos sociales. Téngase en cuenta que hasta ahora los estudios habían trasladado al ejército de Cuba (tanto regular como de milicias) el epicentro de las actividades militares en la Isla, incidiendo en la gran importancia del situado como factor catalizador de la economía local habanera. Sin embargo, ahora sabemos que el gasto militar asociado a la construcción naval fue en la segunda mitad tan importante como el del ejército, y en algunas etapas, incluso superior. Para explicar esto, debemos observar nítidamente el papel de las élites locales y analizar con detenimiento sus intereses.

La rápida y tradicional infiltración de una gran parte de la nobleza de toga habanera en los estamentos del ejército, había colapsado las posibilidades de ascenso y promoción social (así como de negocios) de una parte significativa de la otra élite. No olvidemos aquí el importante papel que jugaba el fuero militar como tradicional baluarte de los intereses grupales de la gran élite habanera. Esto explicaría por qué a lo largo del siglo XviII fueron los sectores medios y bajos de la élite habanera quienes vieron en el astillero un camino paralelo (y más rápido) para un rápido ascenso en los escalones de la sociedad de La Habana. Los negocios relacionados con el astillero supusieron para esta élite una manera de obtener ese poder y esa gloria que tanto brillo daba a las grandes familias locales. El servicio a la Corona mediante la firma de suculentos asientos navales representaba el triunfo de sectores interesados en imprimir a su posición la fuerza y el empuje cercenados por la gran élite local. La pugna entre ambos sectores (que en realidad enfrentaban al ejército y a la marina) tiene su expresión más evidente en los constantes enfrentamientos durante las dos últimas décadas del siglo xVIII por el control de la madera cubana.

En efecto, los datos indican que, hacia final de siglo, la madera se había convertido en el caballo de batalla más importante para dirimir la capacidad de influencia sobre los asuntos militares, aunque desde ópticas diferentes. La gran élite habanera defendía sus privilegios económicos particulares mediante una cerrada pugna por el control de la madera para los negocios del azúcar y el tabaco, a cambio de suculentos préstamos al ejército, y su tradicional fidelidad copando los altos cuadros de la oficialidad de la isla. Por su parte, los sectores medios y bajos de la élite, veían en el control de las maderas una manera de actuar en función de los deseos de la Marina, que no eran otros que aumentar exponencialmente la construcción de navíos. Esta élite ofrecía, a cambio, contratas navales muy sugerentes y beneficiosas para la Corona, préstamos para sostener el arsenal cuando el dinero mexicano no llegaba, y una lealtad no menor, aunque vinculada a la marina.

Como resultado, cuando en 1806 el astillero dejó de funcionar a efectos prácticos, la batalla había sido ganada por la gran élite, entre otros motivos, por 
los bruscos cambios de la política naval de la década precedente. ¿Qué ocurrió? Aunque aún estamos lejos de dar una respuesta definitiva, parece que la obtención de recursos dinerarios de América fue un objetivo preferencial de la política española de la última década del siglo xviII, y eso ahogó las posibilidades de un crecimiento sostenido de la marina de guerra, que tradicionalmente había fagocitado enormes sumas del presupuesto estatal. La gran élite habanera ofreció a Madrid la posibilidad de «olvidarse» de los enormes gastos del ejército de Cuba ofreciendo enormes préstamos y garantizando la fidelidad de la Isla, a cambio, obviamente, de que defendiera sus intereses mercantiles. El resultado fue que después de 1806 una parte significativa de las élites medias habaneras vieron languidecer su posición socio-económica en beneficio de una élite poderosa y con brillo en el escudo de armas. El problema resultante no fue otro que, después de un siglo de ímprobos esfuerzos, el gran astillero de La Habana sucumbió como factor esencial de la potencia naval de España.

\section{BiBLIOGRAFÍA}

Amores Carredano, J. B.: «El intendente de La Habana Juan Ignacio de Urriza y la política imperial de Carlos III (1776-1787)», Navarros en la Monarquí española en el siglo XVIII, (Agustín González Enciso, ed.), Pamplona, 2007, pp. 185-214.

Arango, R.: La Sacarocracia: Historia de La Aristocracia Azucarera Cubana, Miami, 2006. Arrozarena, C.: El roble y la ceiba: historia de los vascos en Cuba, Tafalla, 2001.

Bernal, A. M.: España, proyecto inacabado. Costes/beneficios del Imperio, Madrid, 2005. Cadenas, V. (comp.): Caballeros de Carlos III. Extracto de sus expedientes (1771-1847), vol. 4, Madrid, 1982.

Cadenas, V:: Caballeros de la Orden de Santiago que efectuaron sus pruebas de ingreso durante el siglo XIX, Madrid, 1993.

- (comp.): Extracto de los expedientes de la Orden de Carlos III, 13 vols., Madrid, 1979. Vol. 6.

Cervere, G. P.: «La bahía de La Habana. Apuntes para su historia», Revista de Historia Naval, No. 73, 2001, pp. 59-67.

Cervera, G. C.: Inglaterra y La Habana, 1762, La Habana, 2007.

Chevalier, F.: La formación de los latifundios en México, México, 1976. PMCid:PMC1334886

Cortadellas, R. N.: Genealogías habaneras, Madrid, 1979. Vol. 2.

Crespo Solana, A.: «La acción de José Pati-o en Cádiz y los proyectos navales de la Corona en el siglo XviII», Revista de Historia Moderna y Contemporánea, no 6-7, 1994.

De La Pezuela, J.: Ensayo histórico de la isla de Cuba, Nueva York, 1842.

De La SAGRA, R.: Historia económico-politica y estadística de la isla de Cuba, La Habana, 1831.

De La Torre, J. M.: Habana antigua y moderna, La Habana, 1857. 
Díaz Blanco, J. M.: Asi trocaste tu gloria. Guerra y comercio colonial en la España del siglo XVII, Madrid, 2012.

Fornes, L.: Cuba. Cronología: cinco siglos de historia, política y cultura, Madrid, 2003.

GÁrATe, M.: Comercio ultramarino e ilustración. La Real Compañia de La Habana, San Sebastián, 1993.

García Del Pino, C.: «La construcción naval en Cuba hasta fines del siglo xviII. Sinopsis», Revista de la Biblioteca Nacional José Martí, enero-marzo, 1999, pp. 25-30.

- : «El arsenal de La Habana durante el siglo XviII», La Habana, puerto colonial, siglos XVIII-XIX, Madrid, 2000.

García Fuentes, L.: El comercio español con América, 1650-1700, Sevilla, 1980.

— : «En torno a la reactivación del comercio indiano en tiempos de Carlos II», Anuario de Estudios Americanos XXXVI, 1979.

Gómez, J. M.: Memoria sobre la conservación del puerto de La Habana, Santiago de Cuba, 1831.

González-Ripoll, M. ${ }^{a}$ D.: Cuba, La Isla de los Ensayos-Cultura y Sociedad (1790-1815), Madrid, 1999.

Humboldt, A.: Ensayo político sobre la isla de Cuba, París, 1827.

Kuethe, A. J.: «Havana in the Eighteenth Century», Atlantic Port Cities, Economic, Culture and Society in the Atlantic World, 1650-1850, 1991.

Kuethe, A. J. y Serrano Álvarez, J. M.: «La pérdida de la fidelidad cubana: una perspectiva del siglo xviII», en Nación y cultura nacional en el Caribe hispano, Praga, 2006.

— : «El astillero de la Habana y Trafalgar», Revista de Indias, 67, n. 241, 2007, pp. 763-776.

Leiva, E. y Torres Cuevas, E.: Presencia y ausencia de la Compañia de Jesús en Cuba, Madrid, 2005.

PMCid:PMC1151966

Lohmann, G.: Los americanos en las Órdenes Nobiliarias, Madrid, 1993. Vol. 2.

MARICHAL, C. y Von Grafenstein, J. (coords.): El secreto del Imperio español: los situados coloniales en el siglo XVIII, México, 2012.

Marrero, L.: Cuba: Economía y Sociedad, Santiago, 1972.

Moreno Alonso, M.: «Consideraciones de Humboldt sobre las élites indianas», Élites urbanas en Hispanoamérica, Sevilla, 2005, pp. 180-196.

Navarro, L.: «Política exterior: la guerra», América en el siglo XVIII: los primeros Borbones, vol. XI-1, Historia General de España y América, Madrid, 2010. pp. 117-140.

Ortega Pereyra, O.: El Real Arsenal de La Habana : la construcción naval en La Habana bajo la dominación colonial española, La Habana, 1998.

Parcero, C.: La pérdida de La Habana y las reformas borbónicas en Cuba (1760-1773), Valladolid, 1998.

Prat De Padua, M. y Matamoros Aparicio, D.: «La organización del astillero de La Habana durante el siglo XvIII», Anuario de Historia de América Latina, 34, 1997, pp. 89-103.

Quintero, J.: «La madera en los pertrechos navales», Tiempos Modernos, 10, 2004. 
Rosain, D.: Necrópolis de La Habana: bistoria de los cementerios de esta ciudad: con multitud de noticias interesantes, La Habana, 1875.

Serrano Álvarez, J. M., Allan, J. Kuethe, A. J.: «La familia O’Farrill y la élite habanera», Las élites urbanas en Hispanoamérica, Sevilla, 2005.

Serrano Álvarez, J. M.: «Juan de Acosta y la construcción naval en La Habana (17171740)», Revista de historia naval 24, n. 93, 2006, pp. 7-32.

—-: «La defensa naval de la gobernación de Cartagena de Indias, 1650-1700», Guerra y Sociedad en la Monarquía Hispánica. Política, Estrategia y Cultura en la Europa Moderna, (1500-1700), Madrid, 2006, pp. 1007-1023.

Serrano Álvarez, J. M., Ruiz Rivera, J. B. y Mogollón, J.: «¿Por qué cayó Cartagena de Indias en 1697?», en Cartagena de Indias en el siglo XVII, Cartagena de Indias, 2007, pp. 527-550.

Serrano Álvarez, J. M.: El astillero de La Habana y la construcción naval, 1700-1750, Madrid, 2008.

— : «La revitalización del Astillero de La Habana en época de Lorenzo Montalvo, 17651772», Revista de historia naval 27, n. 105, 2009, pp. 71-100.

—.: "Los inicios del astillero de la Habana en el siglo Xviri y la influencia francesa», História, São Paulo, n. 1, 2011, pp. 287-304.

Tepaske, J. J.: «La política española en el Caribe durante los siglos XviI y XviII», en La influencia de España en el Caribe, La Florida y La Luisiana, 1500-1800, Madrid, 1983, pp. 61-79.

Valdés, A: Historia de la isla de Cuba, y en especial de La Habana, La Habana, 1813.

VÁzquez Cienfuegos, S.: «La Habana británica: once meses claves en la Historia de Cuba», en Metodología y nuevas líneas de investigación de la Historia de América, Burgos, 2001. 